ARTICLE HISTORY: Received: October 20, 2021 Accepted: December 11, 2021 Published: December 19, 2021

\title{
QUALITY ASSURANCE OF HIGHER EDUCATION IN THE CONTEXT OF REGIONAL AND INTERNATIONAL INTEGRATION IN VIETNAM CURRENTLY
}

\author{
Vu Van Khoa \\ PhD student \\ Faculty of Education Management, \\ Hanoi National University of Education \\ Hanoi, Vietnam
}

\begin{abstract}
Quality assurance plays a significant role in enhancing the quality of higher education nowadays. Resolution No. 29-NQ/TW dated November 4, 2013, the Central Executive Committee (Session XI), on "fundamental and complete reform in education and training, serving industrialization and modernization in a socialist-oriented market economy and international integration" identified quality analyses as one of the tasks and solutions to radically and considerably renovate education and training. The paper provides a broad overview of some issues on quality control in advanced education and then suggests some measures to strengthen the quality of academic training in Vietnam ahead of the current regional and international integration trend.
\end{abstract}

Keywords: Quality assurance, quality control, quality culture, higher education, Vietnam

\section{Introduction}

In the context of Doi Moi (Innovation - reform period in modern Vietnamese history, starting in 1986), integration, globalization, as well as a competitive market mechanism, inspection of quality becomes a crucial element for the existence and sustainable development of higher education institutions.

Refurbishing and ameliorating the quality of education and training are the essential requirements for economic, cultural, and social growth. Before renewal demands, at the 11th National Congress of the Communist Party (January 2011), in the Platform for National construction in the period of transition to socialism (supplemented and developed in 2011), affirmed that: "The mission of education and training is to raise intellectual standards of the people, train human resources, cultivate talents, and make an important contribution to building Vietnamese culture and people. The primary national strategy is to develop education and training alongside science and technology development. Investment in education and training is an investment in development. It is necessary to strongly and broadly transform education and training according to the development needs of society and upgrade its quality in the direction of standardization, modernization, and socialization, effectively serving the cause of national construction and defense. It is vital to promote a learning society, creating opportunities and conditions for all citizens to have lifelong learning". Implementing the Party's above stance has posed a challenge for education and training in general and academic institutions in particular. Improving the quality of education and training is inevitable and a leading task toward developing a highly rated workforce possessing the capacity, qualities, and skills to meet the program outcome standards for each specific profession currently. It can be argued that ensuring the quality of education is a critical mission and solution to effectively fulfill the views of the Party and the State in the national development strategy.

In recent years, the Party and the State have carried out many methods that have strengthened the quality of education and training in universities. Therefore, boosting the capacity of the quality assurance system is considered a determinant of the training quality as well as the presence and progress of each higher education facility. It's also the key to creating a quality culture.

\section{Quality assurance in tertiary institutions in Vietnam}

Quality evaluation in higher learning is widely adopted worldwide to maintain standards and continuously improve the quality of post-secondary education. It is used as a general term at different levels and methods, depending on each country's culture and socio-economic development. In the world, there are more than 100 countries with quality assessment systems in tertiary education. However, most of these systems were formed in the 90s (of the 20th century) to adapt to the growth in the scale of higher education (especially the rapid rise of mass and private university training). Many countries have overcome through great upheaval, so they have to change the higher education system. Quality management is perceived and executed differently among countries. However, it was not until the early years of the $21 \mathrm{st}$ century that Vietnam began to apply this policy. It was marked by establishing the Office of Quality Assurance and Accreditation in the Training (in 2002). The most outstanding milestone is the formation of the General Department of Educational Testing and Accreditation (GDETA), a department of the Ministry of Education and Training (MoET), in 2003 with the mission of supporting the Minister of Education and Training in managing the educational quality examination and inspection. 
There are many interpretations of the term of quality assurance. However, Circular No. 62/2012/TT-BGDDT, dated December 28, 2012, promulgating regulations on the process and cycle of accreditation of education beyond high school and professional secondary education by the Minister of Education and Training stated: "Educational quality is the achievement of an academic institute's or program's stated objectives, as well as the requirements of the Law on Education, the Law amending and supplementing some articles of the Law on Education, and the Law on Higher Education, to meet the needs of utilizing human capital assets for the socio-economic development of the community and the country".

Thus, quality testing in education can be understood as a form of quality management, accomplished before and during education. It aims to prevent errors in the educational process from creating poor-quality "educational products" (educational products are the graduates). According to the Vietnamese standard, quality assurance is defined as all planned and systematic actions performed inside a quality system and proved essential for establishing satisfactory confidence that the entity (object) will completely meet the quality criteria. It is a means of making products free from defects caused by errors in manufacturing or education, so quality is entrusted to each person involved in this progress. Thanks to this idea, creating a system of quality standards when applying the quality assurance model is paid more attention so that those who directly make outcomes must be aware of the importance of quality, know how to achieve higher quality, and desire to do it themselves. Moreover, they will entice others to do like they do or even better. Therefore, quality research in education is a system of planned measures and activities conducted inside and outside the school and proven to be vital to create confidence that the activities and products (learners) will fully satisfy the demands of educational quality under the program outcome standards.

Quality assurance includes internal quality assurance and external quality assurance. Schools effectuate internal quality assurance, which is the most important factor, helping them create quality actively. On the other hand, external quality assurance is carried out by other authorities (including accrediting agencies).

\section{Achievements and restrictions}

\subsection{Achievements}

Over the years, the education industry has achieved several outstanding accomplishments in terms of quality assurance and accreditation in education:

- Referring to international experience to apply for quality control and accreditation following the reality of Vietnam.

- Developing and issuing a system of legal documents and guidelines on certifying the quality of education entirely to implement activities for educational quality accreditation on a national scale.

- Building the quality assurance system inside the higher educational institutes. Until April 2021, there were seven domestic accrediting organizations, of which two of them were newly established but had not yet been licensed to operate. The staff in this sector is increasingly being strengthened. Around 2,000 people have completed training courses for accreditors, and 346 people have been licensed to practice.

- International cooperation in quality assurance and accreditation in education is heightened, especially with ASEAN countries, including the ASEAN University Network-Quality Assurance (AUN-QA) and regional and international quality assurance networks (like INQAAHE, APQN, and AQAN...).

- The perception of administrators, lecturers, staff, students, and society towards this task has changed positively. Quality has become a vital aspect for schools.

\subsection{Restrictions}

However, quality assurance and accreditation in advanced education have encountered many challenges such as:

- Human and financial resources to carry out the task are limited.

- Officers and lecturers at education facilities are not fully aware of approaching and accomplishing this duty. The inspection team is small, and the capacity of some of them has not fit the criteria.

- The progress of putting quality accreditation into practice is still slow, especially for inspecting the quality of training programs. The results have not met the set goals, and some universities have not actively engaged in this task.

- Under the terms of the Law modifying and augmenting some articles of the Law on Higher Education, the formation and rearrangement of accrediting bodies in public education are still sluggish and face many obstacles.

- Some documents governing processes and standards for evaluating the quality of training establishments and training programs, accreditors, the assessment and supervision of accrediting agencies, and professional guidelines have not been updated, supplemented, or issued on time. Furthermore, the current quality assurance mechanism has not created independence among the three activities: self-assessment (by institutions of higher learning), external assessment (by an independent agency outside schools), and recognition (by a State management agency in higher education, or the association of universities).

- The quality standards are not yet used for stratification in the higher education system to be a basis for the State's investment decisions.

- The information system serving the evaluation process is not synchronized, and its transparency has not met the set requirements. 


\section{Some orientations to continue intensifying the efficiency of activities in the quality assurance systems at higher education facilities.}

With the view that all activities aim to achieve strategic goals of education and training, meet stakeholders' requirements, and constantly improve quality, institutes of higher education focus on fulfilling some core activities in the context of international integration with lots of opportunities and challenges. Each of them needs to do well in some of the following aspects:

Firstly, developing and operating an internal quality assurance system are fundamental tasks.

The internal quality assurance system should be established and managed consistently from the Board of Directors to all school divisions. The Board of Directors builds a quality assurance strategy including plans, policies, activities, and stakeholder engagement, promoting training and cultivating quality management to meet strategic goals. Moreover, the appropriate measures should be taken to involve people in developing the quality assurance plan to raise their commitment.

It means that institutions of learning need to have a quality assurance policy that is publicly available and a part of strategic management. Internal stakeholders should build and implement this policy via appropriate structures and processes with the involvement of external stakeholders. Policies and procedures are the foundations of a quality control system because they create uniformity, establish a continual improvement process, and contribute to educational centers' accountability. The quality management system supports developing a quality culture in which internal stakeholders are responsible for the quality and are involved in quality evaluation at all divisions. The quality policy or statement must be stated and made public to foster a quality culture. Quality assurance policies are most effective when they represent the connection between research, learning, and teaching while also taking into account the context in the home nation, the circumstances, and the strategic solutions of training institutes.

The division of testing and quality assurance is a permanent one that actively advises the Board of Directors in creating quality assurance programs and plans, as well as tools for performing, checking, and evaluating. Thanks to that, it can organize, monitor, supervise, and coordinate well with implementing divisions.

Each department in a training establishment must have dedicated officers in charge of helping leaders carry out quality assurance and self-assessment activities about their department and training programs. At the same time, it needs to coordinate with the office of testing and quality assurance to complete remedial activities after accrediting and other jobs according to the school's process and regulations on quality control.

In addition, it is momentous to focus on increasing the professional capacity of the team working in quality management. Extending policies, strategies, and plans for training and cultivating to be suitable with the context in each development stage of the educational center plays a pivotal part.

Secondly, it is principal to extend the use of monitoring tools.

Universities should maintain and perform well the training process. In addition, they need to conduct quality surveys well, collect feedback from relevant people on training and scientific research activities to serve the community. Developing and fulfilling objectives on quality standards and promoting scientific research in each educational institution is urgent.

Creating an environment that is convenient, easy, and supportive for activities on quality control is essential. Relevant departments should be instructed to participate in schemes for quality assessment actively. Programs about training and fostering professional knowledge in quality assurance need to be practical. The critical point is that they not only provide learners with some concepts or theories but also help them do the main task according to their position.

Thirdly, academic institutions should use assessment tools.

It is necessary to synchronously develop monitoring and evaluation tools, separate quality assurance processes, specific quality control tools, especially the procedures for correcting or advancing defects discovered through evaluation. Moreover, it is needful to pay attention to effective construction, compilation, exploitation, and use of question banks for graduation and final exams. Universities shall assess well the outcome standards of training disciplines or majors.

Fourthly, it is indispensable to continue reviewing, supplementing, renewing, and carrying out quality assurance processes.

The opportunities, power, especially international experience, and the understanding of national standard universities should be utilized to strengthen the capacity of the quality assurance system. Research that mainstreaming appropriate quality assurance activities into programs and projects is a positive and effective measure. Procedures for assuring the quality of learners, personnel, and facilities and support for students need to be focussed on synchronous testing and planning for addition, completion and refresh.

Fifthly, quality assurance tools need to be developed and used commendably.

Applying the internal quality management model and quality standards shall be carefully considered because they must be suitable to the characteristics of the national education and training and must be "fitted" with education institutes. Pursuing excessive-quality standards not only brings burden but also degrades the training quality at schools. In addition, the universities shall have a strategy to exploit the achievements in the past time to increase their prestige and value in the national education system. This task is concretized by some of the following tasks: 
- Develop quality assurance manual;

- Building a database on the information system about internal quality assurance;

- Regularly informing all staff and lecturers about the importance of quality control in the current context;

- Planning strategies for quality assurance.

It is vital to analyze strengths, weaknesses, opportunities, and challenges in each period and specific circumstances to find solutions. The most important thing is to continuously boost the quality of education and training in higher education establishments, meeting standards when assessing the training quality.

Sixthly, establishing a quality assurance system is significant for the development of a quality culture.

Building a quality management system and a quality culture appropriate for the unique characteristics of education and training takes time and effort. Immediate material benefits and traditional teaching or managerial habits might impede the internal quality control system and forming a quality culture. However, it's arduous to get education quality right away. Obviously, there will not have quality education without the creative labor of teachers and educational administrators. Therefore, educators need to work diligently and innovatively to train the graduates who are high standard and useful to society.

Finally, establishing a legislative framework to assist educational establishments in quickly implementing qualitycontrol measures is indispensable.

The direction as well as specific and appropriate regulations, issued promptly to encourage highly and binding, is an important legal premise for the maintenance and development of the quality assurance system of academic institutions. In particular, the management agencies shall have appropriate financial policies and allocation of funds among schools that have met and have not met the quality standards.

\section{Conclusion}

For Vietnamese higher education, the trend of globalization and international integration has brought both benefits and drawbacks. Therefore, quality assurance is essential to upgrade the quality of education and training at universities and fulfill the demands of the Fourth Industrial Revolution. Strengthening the direction and effective performing quality control in tertiary institutions are the decisive factors contributing to advancing the quality of training and satisfying the requirements of training the first-rate workforce in the current period of international integration.

\section{References}

1. Ministry of Education and Training, Proceedings of the conference summarizing the quality assurance and accreditation of higher education and pedagogical colleges from 2011 to 2020.

2. Viet Nam Government Portal. Development strategy on education 2011-2020. Url: http://vanban.chinhphu.vn/.

3. Le My Phong, Nguyen Thai Son. Overview of Quality Assurance and Accreditation in Vietnamese Higher Education. Department of Assessment and Quality Accreditation, Ministry of Education and Training, 2021.

4. Nguyen Xuan Thanh. Overview of quality assurance and accreditation in education in Vietnam. Papers reported at the Conference of the Central Committee for Propaganda, held on the afternoon of November 6, 2012.

5. Resolution No. 29-NQ/TW - 8th Conference of the Central Executive Committee (Session XI) on a fundamental and complete reform of education and training, Hanoi.

6. Pham Minh Muc. Some solutions for ensuring the quality of education in the current time // Journal of Education Management. 2017. Vol.9, No.10.

7. Planning the network of universities and colleges between 2006 and 2020.

8. SEAMEO. Developing a quality assurance framework for Southeast Asian countries, 2002.

9. Statistics of Department of Assessment and Quality Accreditation, Ministry of Education and Training. Url: https://moet.gov.vn/giaoducquocdan/khao-thi-va-kiem-dinh-chat-luong-giao-duc/Pages/ Default.aspx?ItemID=747. 